\title{
O Estado no Plano Político Estratégico do MST: breves considerações sobre a aproximação com o executivo do Estado durante o Governo Lula
}

The State in the MST's Strategic Political Plan: brief considerations on the approximation with the State executive during the Lula Government

Jetson Lourenço Lopes da Silva ${ }^{1}$.

1 Universidade Federal de Sergipe, Departamento de Serviço Social, Brasil, E-mail: jetsonlourenco@gmail.com, ORCID: https://orcid.org/0000-0002-7495-9148

A R T ICLE IN FO

Article history:

Received 2021-05-15

Accepted 2021-06-29

Available online 2021-06-29
Palavras-chave: Estado. MST. Questão agrária. Reprodução capitalista.

Keywords: Agrarian question. State. MST.

Capitalist reproduction.

RESUMO. O presente trabalho tem por finalidade discorrer brevemente sobre a relação entre o Movimento dos Trabalhadores Rurais Sem Terra (MST) e o Estado, que se apresenta no plano estratégico-político desse movimento social a partir dos programas de reforma agrária que concebeu ao longo de sua trajetória histórica. Vale lembrar, em tais programas estão não só sua concepção e proposta de socialização da terra ou de reforma agrária, como também estão expressos a programática política estratégica que projeta para o conjunto da sociedade. Destarte, aqui foi realizado um estudo aproximativo de alguns programas de reforma agrária elaborados pelo MST, em que se analisa e se tece considerações sobre a relação que costura com o Estado. Observou-se que o aparato estatal aparece como uma mediação importante para o MST, seja pela pressão imediata para efetivação da reforma agrária, seja porque, do ponto de vista mais geral, o Estado assume relevância fundamental para viabilidade do projeto político que concebe. No entanto, o mesmo Estado que buscou aproximação durante o Governo Lula serviu de alicerce institucional para reprodução do capitalismo dependente do Brasil, que tem correlação direta com a questão agrária.

ABSTRACT. This paper aims to briefly discuss the relationship between the Landless Rural Workers Movement (MST) and the State, which is presented in the strategic-political plan of this social movement based on the agrarian reform programs it conceived throughout its historical trajectory. It is worth remembering, in such programs there is not only its conception and proposal for land socialization or agrarian reform, but also the strategic political programmatic that it projects for society as a whole is expressed. Thus, an approximate study of some agrarian reform programs elaborated by the MST was carried out here, in which it analyzes and makes considerations about the relationship it sews with the State. It was observed that the state apparatus appears as an important mediation for the MST, 
either because of the immediate pressure to carry out the agrarian reform, or because, from a more general point of view, the State assumes fundamental relevance for the viability of the political project it conceives. However, the same state that sought rapprochement during the Lula government served as an institutional foundation for the reproduction of capitalism dependent on Brazil, which has a direct correlation with the agrarian question.

\section{Introdução}

Desde os primeiros anos de sua consolidação o Movimento dos Trabalhadores Sem Terra (MST) tem apresentado uma relação de aliança e proximidade política com o Partido dos Trabalhadores (PT). Relação que, para além de estratégica, se caracteriza como orgânica, já que muitas lideranças do movimento também integram esse partido. Por quase toda a primeira década de entrada deste século, mais precisamente, no primeiro ciclo correspondente aos governos petistas, o MST apresentou uma relação mais aproximada ou menos conflitiva com parte do aparato estatal. Destarte, tal aproximação teve sua articulação mais estabelecida através das relações construídas com o Poder Executivo do Estado durante os dois mandatos do Governo Lula.

Dessa forma, o objeto desse trabalho é problematizar, ainda que brevemente, sobre algumas mediações e contradições, possíveis de se vislumbrar ao analisar a relação entre o MST e o Estado estabelecida em sua programática política, de modo que conduziu a aproximação com instituições do Poder Executivo estatal durante o ciclo da gestão petista ente 2003-2010. É importante frisar que no plano estratégico dos Sem Terra ${ }^{1}$ o Estado está afigurado como uma mediação fundamental para viabilizar seu projeto político. No horizonte político deste movimento social o aparelho estatal aparece tanto para realização de alguns de seus interesses e necessidades imediatas quanto para impulsionar seu projeto político mais geral ou para o conjunto da sociedade. No entanto, esse mesmo Estado é o espaço institucional que tem organizado as condições para reprodução do capitalismo nacional dependente, por meio de alicerces políticos e econômicos que determinam as bases de manutenção estrutural da questão agrária no Brasil.

\section{Procedimentos metodológicos}

Para apreensão do movimento do objeto dessa pesquisa na totalidade capitalista em que está inserido, o método assentado no Materialismo Histórico Dialético foi indispensável. Mediante esse método foi possível partir da aparência fenomênica, sua primeira mediação, e num processo de sucessivas aproximações construir as categorias simples de leitura do movimento do objeto. A partir disso, num aprofundamento ou complexificação das categorias, apresentou-se as mediações na totalidade da reprodução social.

É imprescindível lembrar que a totalidade não se confunde com a apreensão de toda as dimensões da realidade. De modo, que se entende essa categoria como a compreensão de que as dimensões da realidade são indissociáveis e estão em constante correlações ou em múltiplas determinações umas com as outras. Ou seja,

\footnotetext{
${ }^{1}$ A expressão Sem Terra, escrita com as iniciais maiúsculas, refere-se ao sujeito coletivo Movimentos dos Trabalhadoras Rurais Sem Terra (MST).
} 
que as mediações que compõe a realidade estão interligadas, implicadas entre si e determinando umas às outras num processo contínuo e contraditório de reprodução de relações sociais historicamente estabelecidas.

Assim, no Materialismo Histórico Dialético 0 desenvolvimento do conhecimento sobre os fenômenos sociais ocorre mediante aprofundamento na explicação dos "[...] condicionamentos históricos como também [...] as suas formas gerais e a sua essência [...]" (LUKÁCS, 1989, p. 124). Por conseguinte, o elo entre o particular e o universal, bem como a historicidade do objeto são imprescindíveis no percurso de conhecimento que se funda nessa tradição.

O ponto de partida da pesquisa requereu operações empíricas com o objeto para mapear ou realizar triagem de fatos e apanhar relações entre eles. Para que a pesquisa superasse o nível das aparências e do dado imediato foi fundamental a reflexão abstrata e com denso suporte teórico sobre esse dado aparente e imediato. Pela natureza do objeto se compreende que a pesquisa apresentou natureza qualitativa, pois privilegiou a análise de microprocessos através do estudo das ações e do horizonte político de um determinado sujeito coletivo, buscando desvelar a relação desses microprocessos com o contexto mais amplo do ser social e histórico (TRIVIÑOS, 1987). Dessa forma, os procedimentos metodológicos contemplaram quatro momentos, que não necessariamente foram operacionalizados nessa ordem linear: 01) Historicização do objeto de estudo; 02) Reconstrução teóricometodológica do objeto de estudo; 03) Pesquisa empírica ou de campo; 4) Processamento analítico das informações capturadas.

O processo de historicização do objeto se deu mediante a construção histórica da questão agrária no Brasil e sua relação com a acumulação capitalista dependente nas relações econômicas internacionais. Isso foi importante para se pensar o desenvolvimento histórico do MST e do projeto político que o orienta na sua relação com o Estado, ora expresso nos programas de reforma agrária que elaborou. Por conseguinte, a reconstrução teórico-metodológica do objeto foi construída a partir do enriquecimento de conceitos ou categorias analíticas mediante acesso a literaturas produzidas por pensadores e/ou pesquisadores com contribuição na área temática.

No plano da pesquisa empírica o estudo se valeu da apreensão de fontes primárias e fontes secundárias, então presentes no: Programa de Reforma Agrária do MST - 1984; Proposta de Reforma Agrária do MST - 1995; Proposta de Reforma Agrária Popular do MST - 2007; Jornal Sem Terra no 160, ano/1996; Jornal Sem Terra $\mathrm{n}$ ㅇ 04, ano/2012. Posteriormente à apreensão de elementos ou material empírico se desenvolveu a análise das informações capturadas, com a apresentação de considerações com perspectiva teórico-crítica tocante às análises.

\section{O papel do Estado na reprodução da questão agrária brasileira}

A acumulação capitalista no Brasil está indissociavelmente articulada com os traços essenciais de sua questão agrária. Essa tem suas marcas históricas e estruturais, de um lado, na concentração da propriedade da terra configurada no latifúndio; na produção agroexportadora que firma o lugar do país na divisão internacional do trabalho; de outro lado, nas lutas sociais pelo acesso à terra por aqueles sofreram sua expropriação.

É bastante sólida a hipótese da dependência do desenvolvimento do capitalismo nacional aos elementos históricos e estruturais da questão agrária. Primeiro, por estabelecer as condições para o movimento de acumulação do capitalismo dependente que caracteriza o país e, segundo, porque na divisão 
internacional do trabalho o Brasil se localiza fundamentalmente como fornecedor de produtos primários para o mercado internacional.

Com o desenvolvimento das relações sociais de produção em que se estabeleceu a industrialização, ficou claro o tipo dependente do capitalismo que amadureceu graças a acumulação primitiva operada pela burguesia rural. A despeito da burguesia industrial brasileira ter assumido, por longas décadas, supremacia política na condução política do país, ela jamais conseguiu imprimir uma direção sem romper com as frações da burguesia rural, portanto sem levar em conta seus interesses econômicos e projeto político, já que em certa medida se constituiu dependente da captura de capital que essas frações realizam com a atividade agroexportadora (OLIVEIRA, 1977).

De um lado se os traços dependentes do capitalismo nacional estão atrelados à dependência econômica aos países do centro capitalista, de outra parte, têm seus laços invisíveis na dependência com a reprodução da concentração fundiária, que estrutura a exportação de produtos primários como necessidade de gerar divisas para obtenção de bens de capital, necessária para montar e manter em atividade a indústria nacional. Isso tudo, além de gerar um montante de divisas para o país preservar o pagamento de juros da dívida internacional.

O latifúndio constitui, em última instância, a base social e territorial de seu controle sobre o Estado, pois é um dos elementos estratégicos de que a burguesia dispõe para compensar, através da monopolização dos excedentes econômicos e do poder político, a instabilidade econômica, social e política inerente ao desenvolvimento desigual e combinado. (SAMPAIO JÚNIOR, 2013, p. 196)

Portanto, de alguma maneira, em razão dessas condições históricas e objetivas, o Estado no Brasil - como instituição de salvaguarda da propriedade privada e responsável por estabelecer as condições necessárias para produção capitalista -, historicamente teve que pautar na sua agenda também os interesses políticos e de estabelecimento das condições de acumulação da burguesia rural, posto que a acumulação desse segmento é em alguma medida imprescindível para realização da reprodução do capital internamente.

A relação estrutural entre questão agrária e reprodução ampliada do capitalismo interno fica um tanto mais explícita, quanto mais se apresenta dentre os elementos da problematização: 1) o papel do Estado no estabelecimento das condições da reprodução do capital; 2) o peso político da burguesia rural dentro do Estado e; 3 ) a interrelação entre capital agrário e os diversos capitais.

$\mathrm{Na}$ esteira das transformações mais agudas do capitalismo no meio rural, inicialmente gestadas nos marcos da década de 1970, a produção no campo passou por um processo de modernização que respondeu mais adequadamente ao mercado oligopolizado, de modo que o setor primário se integrasse ao setor industrial, em especial, como mercado para a indústria de bens de capital e insumos voltada para atividade agrícola e pecuária. Determinado pelo adensamento da entrada do capital internacional no país e as multinacionais que se instalaram nesse período, uma das direções tomadas por esse processo de modernização foi fazer com que 0 agronegócio, para além do caráter primário exportador, assumisse também o viés da agroindustrialização (vide a formação de complexos agroindustriais). 
José Graziano (1982) intitulou o conjunto dessas transformações de modernização dolorosa da agropecuária no Brasil, posto que se tratou de uma modernização efetivada sob a forma de acelerados incrementos de novas tecnologias e técnicas de produtividade, combinadas com iniciativas políticas e econômicas estatais para o favorecimento do setor. Buscou-se com isso modernizar a cadeia produtiva no campo, entretanto, sem alterar as bases da estrutura agrária. Esse processo de modernização dolorosa trouxe imbricado em si componentes detonadores do processo de transformação no meio rural, com implicações não somente produtivas, mas também nas relações sociais de produção no campo.

O grande fiador da modernização (dolorosa) brasileira passou a ser o Estado. De um lado, com o escopo de solucionar o "atraso" no meio rural por meio do aumento da produtividade e da cristalização de relações sociais de trabalho no campo, mantendo-se preservado o monopólio da terra, portanto, sem qualquer alteração da estrutura agrária. De outro lado, o Estado interveio também com o objetivo de incentivar uma maior integração econômica do setor primário e industrial, para favorecer o capital monopolista presente: em subsetores da indústria mecânica e de maquinaria; em subsetores da indústria química e de insumos agrícolas; no subsetor financeiro atuantes na movimentação de créditos para a agropecuária; dentre outros.

A profundidade desse processo de capitalização foi estabelecida pela aliança entre os grandes proprietários rurais com diversos outros capitais, cujo Estado financiou e afiançou as condições de transformação do perfil da burguesia rural em grandes capitalistas rurais, então mais afinados ao movimento de acumulação do capital na era monopolista e de hegemonia do capital financeiro.

Em vista disso,

o desenvolvimento do capitalismo na agricultura, no Brasil, seguiu a chamada via prussiana. Não interessa tanto a denominação, mas o que ela expressa. Na via prussiana, a transformação capitalista não "revoluciona" a realidade agrária preexistente, mas promove uma evolução ou adaptação dela ao capitalismo: por um lado, transforma paulatinamente o latifundiário em grande capitalista (ou seja, promove uma "modernização", em termos econômicos e técnicos, mas raramente em termos político-ideológicos) e os diversos tipos de pequenos agricultores dependentes ou agregados, em trabalhadores assalariados [...]. (GERMER, 2013, p. 312)

Os impulsos dados pelo Estado ao desenvolvimento do agronegócio e para instituição dos requisitos para maior acumulação do capital agrário, possibilitou que os riscos de investimento na atividade agrária diminuíssem e, assim, se afirmassem as condições mais adequadas para a reprodução ampliada do capital nesse setor, o que despertou interesse de corporações econômicas ligadas a capitais industriais, comerciais e financeiros.

Com o intercruzamento entre os diversos capitais (industrial, comercial e financeiro), como processo de centralização do movimento do capital no setor de produção primária, se constituiu um processo em que corporações econômicas do mercado mundial passaram a ter maior domínio sobre a produção e o comércio vinculados ao agronegócio. Uma dominação que se constitui na fabricação e na venda de insumos e químicos, maquinário agrícolas, sementes e uma gama de produtos agroindustriais. 
A dominação e controle por parte dos grandes capitais sobre o setor agropecuário brasileiro, no que veio a se estruturar como agronegócio, engendrou mudanças fundamentais nesse setor, determinadas pela dominação do capital financeiro e de transnacionais no controle dos preços, do mercado nacional e internacional, da aquisição de grandes propriedades de terras; além de imprimir direção à produção em conformidade com as necessidades do mercado mundial em relação a demanda por produtos primários. Em 2010, a partir de dados publicados pelo IBGE, é possível constatar que quase $85 \%$ das terras agricultáveis estavam controladas por empreendimentos vinculados ao agronegócio. Dessas terras, em torno de $80 \%$ são utilizadas para produção de soja, milho e cana.

No que toca especificamente ao domínio exercido pelo capital financeiro, para além da oferta de volumosos créditos para os grandes empreendimentos agropecuários no país, as crises constantes do mercado financeiro levaram essa modalidade do capital a buscar investimentos mais seguros em ativos fixos com alto potencial de especulação no mercado de bolsas, como terras, produção de commodities e bens da natureza.

Muitos bancos passaram a investir, no mercado especulativo de bolsas, na aquisição de ações das mais lucrativas empresas que atuam na produção e comércio do setor agropecuário, ou na produção e comércio de uma diversidade de commodities direcionados à exportação. E, justamente, nesse movimento de financeirização se elevou o controle desse ramo de capital sobre o agronegócio, que passa a depender ainda mais de injeção de créditos para manter elevado o índice de produtividade ou até ampliá-lo, sempre a partir de incremento de alta tecnologia e com uso de insumos. O MST noticiou em seu jornal ${ }^{2}$ mensal que no Brasil, na década passada, a burguesia rural dependeu de adiantamento médio anual de crédito de $R \$ 120$ bilhões de reais por parte de bancos públicos ou privados para viabilizar sua produção.

A engrenagem desse novo movimento do capital, que mobiliza um conjunto de determinações complexificadoras da questão agrária brasileira, vai encontrar lastro, na política de crédito rural arquitetada pelo Estado e no mercado de valorização especulativa de terras, dado a debilidade das instituições estatais em regular esse mercado ou até mesmo atuando para favorecer sua liberdade com determinadas políticas ou legislações.

Desse modo, por intermédio de uma política financeira e econômica, no ingresso do século XXI o Estado vai atuar no sentido de estruturar as condições para instituir um novo projeto de acumulação de capital sob a perspectiva do agronegócio.

Esse processo, do ponto de vista da acumulação de capital, tem o caráter de um pacto da economia política, em sua acepção clássica, e é fundamentado na organização dos interesses hegemônicos de classes sociais no interior do aparelho do Estado. [...] a estratégia de capital financeiro na agricultura depende desses mercados organizados - de terras, de crédito e dos complexos agroindustriais -, e como esses mercados dependem essencialmente da regulação (ou desregulação, conforme o caso) e provisão estatal, o capital financeiro na agricultura irá se configurar como virtual pacto de

\footnotetext{
2 Essa informação foi veiculada na $4^{\text {a }}$ edição impressa do Jornal Sem Terra que saiu no ano de 2012. A partir dessa mesma edição é que se referiu acima sobre o monopólio do mercado agrícola mundial exercido por um número reduzido de corporações.
} 
economia política entre cadeias agroindustriais, grande propriedade fundiária e Estado, tendo em vista viabilizar uma parceria estratégica. (DELGADO, 2012, p. 47-48)

O que se evidencia no decorrer dos anos 2000 é uma expansão do setor primário, determinada pela importância superdimensionada, então adquirida por esse setor dentro da política econômica no Brasil. Isso posto, o agronegócio sob suas múltiplas formas assumirá prioridade na agenda macroeconômica durante os dois mandatos do Governo Lula, como plataforma estratégica do comércio internacional do país, no sentido de capturar excedente de valor, produzido pela renda fundiária, seja na atividade agropecuária e mineral, seja na capacidade especulativa da terra como reserva de valor.

$\mathrm{Na}$ busca pelo equilíbrio da balança comercial nesse período, o agronegócio assumiu centralidade na política econômica. Com isso tornou a vigorar no Brasil

o fenômeno da "reprimarização" do comércio exterior [...]. Mas o sucesso mais imediato da opção primário-exportadora caberá ao governo Lula no período 2003-2007, quando vigorosos saldos comerciais oriundos dessas exportações superam 0 déficit de serviços da conta-corrente, tornando-a superavitária. (DELGADO, 2012, p. 117)

$\mathrm{Na}$ contemporaneidade a questão agrária tenha assumido contornos ainda mais complexos, na conjuntura em análise ela aprofunda seu vínculo estrutural com o processo de acumulação capitalista nacional (e com o movimento do capital em escala internacional), já que se insere na lógica da hegemonia do capital financeiro. E se complexifica também articulado ao capital agroindustrial, bem como articulado com a grande propriedade de terra, dado que a política do Estado alicerça o desenvolvimento dessa articulação.

O processo de modernização da produção no campo, que desenrolou o aprofundamento de capitalização do meio rural no Brasil, encontrou no Estado o principal articulador dos interesses econômicos e políticos das frações de classe dos grandes proprietários de terra, ao tecer costuras com os interesses de mesma espécie presentes na representação do capital monopolista e da hegemonia do capital financeiro. No interstício das três últimas décadas esses interesses se cristalizam no orbe do Estado, fazendo dele o agente mediador institucional entre a burguesia rural e a integração dos diversos capitais. Ainda assim, a dialética da totalidade capitalista presente na reprodução do padrão moderno de produção no campo não deixou de apresentar suas contradições.

Comumente tratada somente pela ótica da produtividade ou pelo viés imediatamente ou exclusivamente econômico, as abordagens das relações sociais de produção capitalista no campo secundarizam as relações políticas, subjetivas e ideoculturais entre as classes que estão nesse terreno da produção. Destarte, são lateralizados as contradições e os conflitos de interesses políticos e socioeconômicos entre as frações de classes que se relacionam no meio rural.

O histórico de conflitos agrários se acentua também como traço da formação social do país e ao mesmo tempo expõe outra ponta de sua questão agrária, a conflitividade entre os sujeitos históricos. Há no Brasil uma longa trajetória de lutas sociais de classes no campo, em que o centro de gravidade dos conflitos está presente na apropriação privada da terra e na organização fundiária necessária para efetivar a produção primária. Em que pesem as diferenças particulares presentes na infinidade dos conflitos agrários no país, essencialmente a luta de classes se 
posiciona no entremeio da opção histórica de modelagem da estrutura agrária, cujo latifúndio e o primado do agronegócio montam base.

Diante da opção histórica de (re)modelagem da estrutura agrária aberta pelo Estado entre as décadas de 1970 e 1980, prevaleceu como processo a alternativa de "modernizar e conservar". Isso repôs o aprofundamento de um conjunto de contradições que, intensificaram os conflitos em torno da terra e pressionaram a emergência de organizações de luta dos trabalhadores do campo. É, nesse sentido, que fundamentalmente a luta de classes assume também posição mediadora da questão agrária brasileira e elemento historicamente imbricado à reprodução capitalista no meio rural.

James Petras (1997) salienta que desde a última década do século XX já se indicava o potencial de conflitividade política presente nas lutas sociais realizadas por sujeitos coletivos que representam os trabalhadores rurais e camponeses, pois são justamente os trabalhadores do campo que vêm reafirmar com maior acuidade a atualidade da teoria social histórico-crítica, em especial sobre o escancaramento da luta de classes.

\subsection{A emergência histórica do MST e a mediação do Estado na programática política}

O MST foi uma das organizações de lutas sociais que emergiu a partir do aprofundamento das contradições da questão agrária no Brasil, decorrente do processo de "modernização dolorosa" do campo.

Alguns dos determinantes fundamentais para gênese dos Sem Terra apresentam aspectos socioeconômicos associados à intensificação do uso da mecânica no processo de trabalho e de produção na agricultura, pois ao dotar a produção agrícola "com características mais capitalistas expulsaram do campo, de uma maneira mais rápida, grandes contingentes populacionais [...]. Com a entrada da mecanização, liberou-se um enorme contingente de pessoas" (FERNANDES; STEDILE, 2012, p. 18).

O Regime Militar, que fez uso do Estado para financiar a capitalização do setor primário e viabilizar sua completa consecução, buscou como saída política para acalmar os ânimos da população expulsa do campo a efetivação de uma política de colonização agrária em regiões do Norte e do Centro-Oeste. No entanto, essa ação resultou em deslocar o conflito para regiões vistas como potencial de expansão de fronteiras agrícolas ou com larga possibilidade de concentração fundiária, impulsionando a propriedade latifundiária ao constituir a terra como reserva de valor para burguesia rural já nos primeiros passos de aproximação ou imiscuída pelos tentáculos do capital financeiro.

Expulsos da terra, uma outra parte da população camponesa migrou para os grandes centros urbanos industrializados do país, constituindo-se naquilo que Marx (2011) designou como população latente ao tratar das formas de existência da superpopulação relativa inerente a Lei Geral da Acumulação Capitalista.

Quando a produção capitalista se apodera da agricultura ou nela vai penetrando, diminui, à medida que se acumula 0 capital que nela funciona, a procura absoluta da população rural. Dá-se uma repulsão de trabalhadores, que não é contrabalançada por maior atração, como ocorre na indústria não-agrícola. Por isso, parte da população rural encontra-se 
sempre na iminência de transferir-se para as fileiras do proletariado urbano [...]. Mas, seu fluxo constante para as cidades pressupõe no próprio campo uma população super relativa latente [...]. Por isso, o trabalhador rural é rebaixado ao nível mínimo de salário e está sempre com um pé no pântano do pauperismo. (MARX, 2011, p. 746)

A despeito de, inicialmente, parcela do contingente de camponeses que migrou para os grandes centros urbanos industrializados ter sido absorvida como mão-de-obra, com a longa onda da crise estrutural da acumulação capitalista ${ }^{3}$ que atingiu o país nos finais década de 1970, essa população se viu sem muitas alternativas, seja diante do desemprego na cidade, seja diante da mecanização do campo. E num cenário de profunda contradições socioeconômicas, de esgarçamento político do Regime Militar e de efervescências das lutas sociais, restou aos camponeses ou trabalhadores rurais sem terra organizarem-se.

Foi substancial para o reascenso da luta organizada dos trabalhadores rurais expulsos da terra o trabalho ideológico da Comissão Pastoral da Terra (CPT), no sentido de (re)despertar a consciência organizativa e a disposição para luta política. Paralelo a isso, colaborou o processo de "redemocratização" do país, que deu a base histórico e social para se colocar de novo em pauta a necessidade de uma reforma agrária radical e profunda. Assim, foi sob esse conjunto de condicionantes históricos, socioeconômicos e políticos que em 1984 o MST se constituiu simbolicamente no "Primeiro Encontro Nacional dos Trabalhadores Rurais Sem Terra" realizado do Rio Grande do Sul.

O Movimento dos Trabalhadores Rurais Sem Terra foi organizado com a finalidade de dar unidade política e programático-orgânica às lutas e organizações camponesas que explodiram em todo o país, especialmente, em regiões onde era (e ainda é) marcante a dominação do agronegócio e a presença do latifúndio improdutivo. Logo tornou-se característico por ser um movimento social de massas com caráter democrático-popular, cujos segmentos da classe trabalhadora, oriunda do meio rural ou não, podem ser incorporados. Ou seja, se estruturou como uma ferramenta política de massas em que estabelece mediações entre os interesses particulares, em torno da luta pela terra, e os interesses mais gerais de classe. Estudos sobre a natureza e estrutura organizativa do MST estabelecem quase um consenso de que se trata de um movimento social, o próprio Sem Terra assim se autodenomina.

Todavia, é possível atribuir também ao MST certa acepção de organização com caráter partidária. Isso, por conseguinte: a forma particular de formação e desenvolvimento histórico do MST; a estrutura organizativa e política de âmbito nacional; a articulação estratégica com organizações políticas dos trabalhadores e setores subalternos; a aliança e aproximação política com partidos que "representam" o campo da esquerda; ao caráter social e político de organização de massas; especialmente, pelo cuidado com a formação de quadros e pela unidade construída no processo histórico em que articula - para além da luta pela terra -, também outras lutas populares. Bem como, pelos princípios organizativos e a elaboração de um Programa Nacional e Popular que expressa os interesses universais das classes subalternas, na medida em que a reforma agrária se vincula a outras reformas estruturantes como projeto nacional.

Dito de outra maneira, por todas as diversas características supramencionadas se pode atribuir que a natureza e estrutura organizativa dos Sem

\footnotetext{
${ }^{3}$ Sobre o debate acerca da crise estrutural do capital é indispensável ver Ernest Mandel (1982).
} 
Terra, para além de se constituir como movimento social camponês, assume também a forma partido.

Para José de Souza Martins (1996), o MST em sua trajetória histórica deixou de ser um movimento social quando se estruturou em organização política de lutas populares e de massas, com isso se firmou como um partido popular agrário. Uma vez que, não apresenta mais

as características de um movimento social. A tendência do movimento social é desaparecer atingidos e esgotados seus objetivos, ou a capacidade de transformar-se numa organização partidária. É o primeiro partido popular agrário que temos no Brasil. (MARTINS, 1996, p. 09)

Por isso, se parte aqui da concepção teórica de que como ferramenta organizativa de luta dos trabalhadores rurais, esse movimento social se constitui igualmente como uma espécie de partido político, um "aparelho" formador de consciência de classe, portanto responsável pela elevação da consciência social e política de setores subalternos. Enquanto uma fração de partido da classe trabalhadora, o MST "opera como uma ferramenta com vinculação a interesses ético-políticos de uma determinada classe e com função de elevação da consciência imediata sindical" (GRAMSCI, 2004, p.72). Dessa forma, a direção e o comportamento político que assume tem papel determinante na esteira da luta de classes de maneira mais geral.

Embora tenha se constituído a partir de uma dimensão imediata da vida social dos trabalhadores rurais, a luta pela terra como condição de subsistência, o MST logo mostrou superação desse momento econômico-corporativo. Com o desenvolvimento histórico logrou saltar para uma organização política de interesse universal, em que incorpora interesses do universo das frações da classe trabalhadora. Daí se caracteriza também por assumir a forma partido ao transcender para uma dimensão ético-política em que o movimento social:

adquire consciência de que seus próprios interesses corporativos, em seu desenvolvimento atual e futuro, superam o círculo corporativo, de grupo meramente econômico, e podem e devem tornar-se os interesses dos outros grupos subordinados. (GRAMSCI, 2001, p.41)

No caso específico da luta que empreende o MST, essa vai se articular à luta de classes em sua dimensão mais geral ou universal presente na continuidade histórica da luta pela reforma agrária. $\mathrm{Na}$ particularidade nacional, a luta pela desconcentração da propriedade da terra e sua socialização apresenta caráter sistêmico, visto que a estrutura e organização fundiária no Brasil é um nó górdio, cuja amarra foi tecida desde a chegada dos conquistadores portugueses e se perpetua até o presente século XXI. A propriedade latifundiária e a produção capitalizada no campo estruturam a dinâmica da acumulação capitalista nacional e são orgânicas ao processo de reprodução do caráter dependente da economia brasileira no cenário internacional, operado pela lógica desigual e combinada do desenvolvimento das relações econômicas no movimento de expansão mundializado do capital, que se expressa na divisão internacional do trabalho entre as nações.

Em assim sendo, na pauta central da luta que trava o MST vem à baila questões seculares conectas à estrutura agrária nacional, pois toca também em 
estruturas sociais, econômicas e numa cultura de dominação política que, por conseguinte, organiza e legitima a sociedade profundamente desigual e de completa subalternização de parcela significativa da população.

[...] as formas externas de desigualdade socioeconômica, cultural, e política imperantes no mundo agrário brasileiro, constituem requisitos sine qua non para a reprodução social do trabalho não pago, semipago ou pago ultradepreciado. Tocar nas condições que dão continuidade inexorável a desigualdades tão extremas e chocantes seria o mesmo que destruir a viabilidade de economias agrárias que não conseguem mercantilizar a força de trabalho, incorporando-se no mercado interno. Dessa perspectiva, o dilema rural brasileiro não se reduz apenas, como muitos pensam, a questões de ordem econômica e técnica. Ele implica e impõe um desafio social em termo especificamente políticos. (FERNANDES, 1981, 197)

A reforma agrária ganha basilaridade entre os pontos fundamentais que toca o projeto societário proposto por esse movimento social. Ela não faz parte da agenda da ordem, pelas estruturas históricas do latifúndio no país e pela funcionalidade imperiosa que assume para o movimento de acumulação capitalista do tipo dependente em que se inscreve a economia nacional no cenário mundial.

Afinal, a intocabilidade do latifúndio, vinculada aos interesses dos diversos capitais que operam no campo, aparece no entremeio da questão agrária como "elemento estratégico do padrão de acumulação e do padrão de dominação do capitalismo dependente como um todo" (SAMPAIO JÚNIOR, 2013, 201).

Por isso que, ao longo de sua trajetória, a luta empreendida pelo MST contra a presença da lógica do capital no campo se afirma num projeto político que se coloca, primeiro, num movimento de tensão com a concentração da propriedade fundiária; segundo, como alternativa em confronto com 0 fortalecimento e predomínio do agronegócio como paradigma produtivo e de desenvolvimento no meio rural.

Ao se constituir como base concreta de organização de luta de classes, com perspectiva de viabilizar a construção da identidade e consciência das frações dos trabalhadores rurais, no seu desenvolvimento os Sem Terra em pouco tempo superou a condição de ferramenta política de luta por interesses imediatos e corporativos, então se constituiu também como organização de luta por um projeto alternativo de sociedade que rompa com a lógica destrutiva capitalista.

Nesse sentido, irá atrelar a bandeira da reforma agrária a outras questões estruturais que se põem atravessadas à realidade nacional, como a estratificação social desigual cristalizada na formação brasileira, no tocante ao caráter de subordinação econômica ao imperialismo internacional e no que toca ao modelo de desenvolvimento no campo sustentado no padrão de produção viabilizado pelo agronegócio.

Logo no primeiro Programa de Reforma Agrária que elaborou já no ano de sua fundação - em 1984 -, chama a atenção que estão na mira como objeto de reivindicações e conquistas a desapropriação de: "1 - Terras das multinacionais e, 2 - Terras dos latifúndios extensivos". Nesse primeiro momento a reforma agrária

\footnotetext{
${ }^{4}$ Linhas políticas presentes no Programa de Reforma Agrária do MST, documento elaborado como plataforma política do movimento social em seu I Encontro Nacional.
} 
assume uma mediação de transformação societária no conjunto programático do MST, ainda que genericamente, já que tem em vista lutar "por uma sociedade igualitária, acabando com o capitalismo".

Com o amadurecimento na caminhada histórica das lutas sociais, sua plataforma política delineia-se mais acuradamente, assim ganha status de eixo dinâmico a pauta da reforma agrária, ora articulada a um projeto de nação, pois "não se trata apenas de uma solução para o problema dos sem-terra, mas faz parte de um novo modelo de desenvolvimento nacional" 5 .

Dessa forma, a luta pela desapropriação e socialização da terra vincula-se a questões estruturais que tocam no modelo de desenvolvimento do país, no que diz respeito a questões internas como: a distribuição de renda; bem-estar social e melhorias nas condições de vida da população brasileira; geração de emprego, dentre outras. Além disso, tais lutas vão tocar em questões externas, especialmente, por meio: da expropriação de propriedades de bens da natureza pertencentes a empresas estrangeiras no Brasil; da reorientação da produção agrícola, sem que essa esteja subordinada aos ditames do mercado internacional; da autodeterminação da soberania nacional frente à dependência ao capital estrangeiro.

No quadro de suas formulações programáticas, a efetividade da reforma agrária ou a sua complementaridade requer uma articulação necessária com uma série de políticas públicas com vista a atingir os interesses estratégicos de ordem estrutural que projeta o MST. Para consecução de sua plataforma política, as instituições estatais aparecem como o terreno imprescindível, em plano mediato ou imediato para concretização dos objetivos estratégicos presentes.

Também em decorrência aos interesses mais imediatos, ou seja, naquilo que toca a sua existência, é indispensável a oferta de uma gama de serviços sociais para sua manutenção como organização política de massas. É nesse sentido que esse movimento social tem que buscar como mediação direta a articulação com diversos espaços estatais, mesmo que se coloque contraditoriamente em tensão com 0 aparato do Estado.

Quando se observa a proposta política do MST se percebe que o Estado desponta como grande mediador para o plano político mais geral do movimento. Dessa forma, advém a perspectiva de estabelecer no Brasil um programa de poder democrático e popular, em que o primeiro passo é a pressão por meio de lutas sociais, para que então se estabeleçam as bases institucionais imprescindíveis para o plano programático traçado. A partir daí o Estado tem papel estratégico, já que a

[...] ação do Estado democrático e popular: [...] dependem necessariamente de que o Estado e todos os poderes nele representados - Executivo, Legislativo e Judiciário - sejam o instrumento de execução dessas medidas. O Estado deve mudar sua natureza atual. Deverá ser gerido democraticamente, com ampla participação das massas e

\footnotetext{
5 Documento lançado pelo MST em 1995 e intitulado "Propostas para Reforma Agrária". Esse documento norteador nasce a partir de sínteses de debates e formulações sobre a Reforma Agrária no III Congresso Nacional do MST.
} 
A partir desse ponto se estabelece uma aproximação histórica desse movimento social com o Partido dos Trabalhadores. Para além de uma relação orgânica com esse partido estabelecida por meio de suas lideranças, a relação com o PT também se firma mediante as orientações políticas que tocam a natureza e papel social do Estado. Pois, as instituições, fundamentalmente, aquelas diretamente ligadas a dimensão gestora ou executiva do Estado assumem papel preponderante para compatibilizar o desenvolvimento do país, na efetivação de uma democracia baseada no poder popular e afirmação da soberania nacional.

Da mesma forma que o Partido dos trabalhadores, que tinha em suas referenciais o Projeto Democrático e Popular ${ }^{7}$, pautado na lógica de ocupação de espaços institucionais para viabilizar conquistas sociais, o MST também vislumbra no Estado significativa importância mediadora para o projeto político que apresenta.

Ante às necessidades estratégicas, político-programáticas e até mesmo de imediata manutenção das condições objetivas do MST, operou-se uma aproximação com espaços do Estado, abertos durante a gestão do PT (entre 2003-2010).

$\mathrm{Na}$ esteira dessa aproximação, diante das exigências de manutenção do movimento social e viabilização estratégica de seus interesses políticos, germinou uma contradição para o MST, determinada em parte pela intervenção mais aproximada com instituições que compõem a estrutura do Estado, que em última instância esteiam a ordem política, econômica e social vigente, ora expressa na condição de capitalismo dependente que caracteriza o Brasil.

\section{Considerações Finais}

O projeto político do movimento social tem como bússola uma ordem social lastreada não só na socialização do trabalho, mas na socialização da riqueza produzida. Para tanto, dada a especificidade da organização e caráter de fração de classe para os trabalhadores expropriados do acesso à terra no Brasil, está colocado ao MST a exigência de uma radical luta pela reforma agrária no país, viabilizada pela pressão e enfrentamento ante ao aparato do Estado por meio de ocupações e outras formas de ação política.

Quando se observa as formulações e o plano estratégico do projeto político do MST fica patente que o Estado está configurado como uma mediação essencial para programática que construiu. Num primeiro momento por meio das lutas sociais que empreende pela reforma agrária. Mas, o fundamental para o MST é que a viabilização do seu projeto político mais geral passa pela mediação do conjunto do aparato estatal. Como articulador da transformação socioeconômica o Estado também tem que, de acordo com o plano estratégico, alterar sua natureza de dominação política.

Dessa forma, no plano político a importância do Estado para seu projeto político fundamentou e determinou, em grande medida, a aproximação do MST com parte do aparato estatal costurada durante a gestão petista no Poder Executivo

\footnotetext{
6 O documento "Proposta de Reforma Agrária Popular do MST" é resultado das orientações formulados para a organização e direção de luta do Sem Terra, no ano de 2007, período conjuntural do 2 o Governo Lula.

7 Há um intenso e polêmico debate se o PT ainda tem como referência o Projeto ou Programa Democrático Popular ou mesmo se esse referencial tem alguma influência hoje na orientação do partido. Sobre as transformações e metamorfoses programáticas do partido sugere-se a leitura de lasi (2006) e (2017).
} 
durante o Governo Lula (2003-2010). No entanto, isso expressou uma contradição para o próprio movimento, uma vez que a gestão executiva desse mesmo Estado foi a base de articulação não do projeto de reforma agrária, mas do fortalecimento das marcas históricas e estruturais da questão agrária no Brasil: o latifúndio, o agronegócio e a produção monocultora direcionada para o mercado externo. Isso, porque são esses o alicerce de reprodução do capitalismo dependente nacional.

\section{REFERÊNCIAS}

DELGADO, Guilherme. Do capital financeiro na agricultura à economia do agronegócio: mudanças cíclicas em meio século (1965 - 2012). Porto Alegre: Ed. UFRGS, 2012.

FERNANDES, Bernardo; STEDILE, João. Brava Gente: a trajetória do MST e a luta pela terra no Brasil. São Paulo: Expressão Popular, 2012.

GERMER, Claus. Perspectiva das lutas sociais agrárias nos anos 1990. A questão agrária do Brasil: o debate na década de 1990. João Pedro Stedile (Org.). São Paulo: Expressão Popular, 2013, vol. 6, p. 309-339.

GRAMSCI, Antonio. Cadernos do Cárcere. Rio de Janeiro: Civilização Brasileira, 2001, v. 3.

IASI, Mauro. As Metamorfoses da Consciência de Classe - O PT entre a negação e o consentimento. São Paulo: Expressão Popular, 2006.

2017.

Política, Estado e ideologia na trama conjuntural. São Paulo: ICP,

LUKÁCS, Gyorgy. Marxismo e Questão de Método na Ciência Social. 0 Marxismo Ortodoxo. São Paulo: Zahar, 1989.

MANDEL, Ernest. O Capitalismo Tardio. São Paulo: Abril Cultural, 1982.

MARTINS, José. $O$ cativeiro da terra. São Paulo: Hucitec, 1986.

Revisando a questão agrária. In: Jornal Sem Terra oํ 160, 1996.

MARX, Karl. O Capital: crítica da economia política. Livro I: 0 processo de produção do capital. Rio de Janeiro: Civilização Brasileira, 2011, vol. 1.

MOVIMENTO DOS TRABALHADORES RURAIS SEM TERRA. Programa de Reforma Agrária do MST - 1984. MST: Porto Alegre, 1984b. Disponível em: http://www.reformaagrariaemdados.org.br/biblioteca/documentos. Acesso em: 23 de dezembro de 2018.

Proposta de Reforma Agrária do MST - 1995. MST: São Paulo, 1995. Disponível em: http://www.reformaagrariaemdados.org.br/biblioteca/documentos. Acesso em: 23 de dezembro de 2018.

\begin{tabular}{ccc} 
& Proposta de Reforma Agrária Popular do MST - 2007. MST: São \\
\hline Paulo, & 2007. & Disponível
\end{tabular} http://www.reformaagrariaemdados.org.br/biblioteca/documentos. Acesso em: 23 de dezembro de 2018.

Jornal Sem Terra. São Paulo: MST, n. 160, 1996. Disponível em: http://www.mstemdados.org/biblioteca/jornal. Acesso em: 09 de setembro de 2018.

OLIVEIRA, Francisco. A Economia da Dependência Imperfeita. Rio de Janeiro: Graal, 1977.

PETRAS, James. Neoliberalismo en América Latina: la izquierda devuelve el golpe. Rosário: Homo Sapiens Ediciones, 1997.

SAMPAIO JÚNIOR, Plínio de Arruda. Notas Críticas sobre a Atualidade e os Desafios da Questão Agrária. In: STEDILE, João Pedro (Org.). A questão agrária 
do Brasil: o debate na década de 2000. São Paulo: Expressão Popular, 2013, vol. 08, p. 189-240.

SILVA, José Graziano da. A Modernização Dolorosa: estrutura agrária, fronteira agrícola e trabalhadores no Brasil. Rio de Janeiro: Zahar Editores, 1982.

TRIVIÑOS, Augusto. Introdução à pesquisa em ciências sociais: a pesquisa qualitativa em educação. São Paulo: Atlas, 1987. 